\title{
Gendering the elites: an ethnographic approach to elite women's lives and the re-production of inequality
}

\section{Luna Glucksberg}

Working paper 7

October 2016 


\section{LSE International Inequalities Institute}

The International Inequalities Institute (III) based at the London School of Economics and Political Science (LSE) aims to be the world's leading centre for interdisciplinary research on inequalities and create real impact through policy solutions that tackle the issue. The Institute provides a genuinely interdisciplinary forum unlike any other, bringing together expertise from across the School and drawing on the thinking of experts from every continent across the globe to produce high quality research and innovation in the field of inequalities.

In addition to our working papers series all these publications are available to download free from our website: www.lse.ac.uk/III

For further information on the work of the Institute, please contact the Institute Manager, Liza Ryan at e.ryan@Ise.ac.uk

International Inequalities Institute

The London School of Economics and Political Science

Houghton Street

London

WC2A 2AE

Email: Inequalities.institute@Ise.ac.uk

Web site: www.Ise.ac.uk/III

@LSEInequalities

(c) Luna Glucksberg. All rights reserved.

Short sections of text, not to exceed two paragraphs, may be quoted without explicit permission provided that full credit, including $\odot$ notice, is given to the source. 


\begin{abstract}
Transfers between generations are a key driver of social and economic inequalities, ensuring that wealth is not redistributed, but accumulated instead in the hands of a small elite, sometimes described as 'the super-rich'. It is crucial to understand how this accumulated capital is socialized and passed down the generations through a labour that I argue is gendered in nature, heavily reliant on women, and currently under-researched. In this paper I address this gap ethnographically, focusing on the gendered labour that women perform to sustain and reproduce the dynastic projects of elite families. I compare and contrast the symbolically distant categories of mothers/wives (Ostrander 1984) and "girls" young women who socialize on the VIP scene, as defined by Mears (2015). Both groups involve biologically female bodies deeply involved in the reproduction of elites but the categories they inhabit, the selves that are both ascribed to them and which they choose to present could not be any more different. In light of this data, elite London emerges as a social space structured around strong hierarchies not just of class but also gender. I therefore argue that it is essential to understand more about the interplay of these two structuring principles within elite spaces, focusing on the 'invisible' labour performed by elite women.
\end{abstract}

Keywords: elites; gender; social reproduction; super-rich; women; accumulation; wealth; class; inheritance

\title{
Editorial note and acknowledgements
}

This paper is based on the ESRC funded project "Life in the 'Alpha Territory': London's 'Super-Rich' Neighbourhoods" (ES/K002503/1) which was led by Prof. Roger Burrows (P.I., Newcastle University) joined by Prof. Mike Savage (LSE), Prof. Caroline Knowles (Goldsmiths University), Prof. Em. Tim Butler (KCL), Prof. Rowland Atkinson (Sheffield University) and David Rhodes (University of York), as well as the author. 


\section{Introduction}

Contemporary elites are never static: they are dynasties, in the making, always. As Savage (2015) argues, following Piketty (2014), we should be thinking about elites in terms of the long dureé: a slow and constant process of accumulation. This process involves not just economic assets - although they are undoubtedly crucial to elite formation processes - but also social, educational and symbolic capitals. It is not, however, just about accumulating capitals: it is about capitals and people, entwined together to forge long lasting dynasties. As an elite wealth manager explained, it's not just about preparing the money for the children. It's preparing the children for the money. What he meant was that it was essential to create the kind of human being who would be capable of handling an inheritance when the time came. Moreover, someone who would be able to increase the capital he would receive (yes, he: more on the gender balance of inheritors later) and then hand it over successfully to the next generation.

It is these processes that I am interested in, and will explore in this chapter: how are these individuals created and reproduced? How are they socialized, how are these practices embodied? I am looking here at the labour of other, female bodies, and their roles in creating uber achieving, "alpha" males. I focus specifically on two categories, but I could have used many others - these two are by no means exhaustive of the roles women play in the reproduction of elites (see Glucksberg 2017 forthcoming). I will compare and contrast the symbolically distant categories of mothers/wives (Ostrander 1984) and "girls" - young women who socialize on the VIP scene, as defined by Mears (2015). Both groups involve biologically female bodies deeply involved in the reproduction of elites but the categories they inhabit, the selves that are both ascribed to them and which they choose to present could not be any more different.

The argument in this chapter is that gender, women and their labour are key to the reproduction of elites. So far, apart from a few exceptions that I will explore later on, gender has not been a particular focus of elite studies, and I address this gap with some ethnographic examples showing just how crucial its role is. The labour women perform often goes unrecognized not just by social scientists but even by the women themselves. This aligns the women in this class with the very well established paradigm of the invisibility of gendered, reproductive labour. Finally, I question the staggeringly rigid gender norms and expectations that I have encountered in my research, and consider whether our understanding of elite reproduction could be enriched by a keener focus on the interplays between gender and class at the top of the social hierarchy.

\section{Literature Review}

Currently, wealth advisors estimate that the biggest wealth transfer event in recorded history will take place between 2007 and 2061, and will consist of $\$ 59$ trillion to be transferred and divided amongst heirs, charities and foundations - and that is in the US alone (Rosplock and 
Houser 2014). Successful transfers of the wealth preserved within families are the main preoccupation of wealthy individuals, according to those who advise them (Wealth-X and UBS Ultra Wealth Report 2014).

Piketty (2014) and others have convincingly argued western nations may have enjoyed a brief period of falling inequality from the twenties to the seventies that was, rather than a trend, almost a blip in a much longer historical trajectory of growing inequality, because of the weight of capital accumulation by the previous generations. Khan (2012) asks "whether elite seizure is an anomaly that will be rectified or a return to the kind of normal dominance experienced for much of history". To put this into context, Oxfam (2015) has released data showing that in 2014 the bottom half of the world's population owned the same as the richest 80 people in the world.

Transfers between generations are a key driver of social and economic inequalities, ensuring that wealth is not redistributed, but accumulated instead in the hands of a small elite, sometimes described as 'the super-rich'. It is crucial to understand how this accumulated capital is socialized and passed down the generations through a labour that I argue is gendered in nature, heavily reliant on women, and currently under-researched.

Indeed, Savage et al (2014) argue that this is currently one of the most important tasks for sociologists:

"What kinds of rituals and symbolic life is characteristic of the super wealthy and the broader elite? What is the role of elite education, of residential and consumption patterns, of friendship and social networks amongst these groups? This is arguably the fundamental sociological question of our age, in exploring the kinds of closure and social and cultural elitism which might now characterize the very highest levels of the social structure. What kind of kinship alliances, elite rituals, and institutional powers do we see around us in 2014?"

(Savage et al 2014: 603)

This concern with the socio-cultural aspects of elite life and reproduction is not, however, signalling a retreat from the structural, economic aspects of elite reproduction. I have described elsewhere how elites ensure their continuous economic and financial dominance through straightforward, long term economic investments and capital accumulation often entrusted to teams employed by wealthy families precisely to look after their affairs, their 'private' or family offices (Glucksberg and Burrows 2017). It would be ill advised to fall into the trap that Khan (2012:368) warns us against, that of mobilizing 'cultural' explanations for the advantaged while looking for structural explanations to do with poverty. Studying the reproduction of inequalities requires first and foremost an awareness that it is the structural conditions of accumulation that capitalism puts in place that work in similar ways to advantage those at the top and disadvantage those at the bottom. The elites are then able to employ 
culture and to some an extent hide and naturalize their own structural advantages, mainly through meritocratic discourse - but the current movements against the $1 \%$ and the 'super rich' show this is by no means an entirely successful hegemonic project.

\section{Gendering the elites}

There were 2,473 billionaires in the world in 2015 according to leading consultancy WealthX, controlling a total wealth equal to 7,683 US billions. $88.1 \%$ of them were males, while $11.9 \%$ were female; the men controlled $88.6 \%$ of the total wealth (Wealth-X 2015-2016 Billionaire Census Highlights). What is interesting for the purpose of this chapter is, apart from the very obvious imbalance that means there are 8.4 male billionaires for each female one, is the marriage patterns of these individuals. $85 \%$ of all billionaires were married in 2015 ; the rate was as high as $88 \%$ for men. In terms of context, in the UK the ONS estimated that $50.6 \%$ of adults were married, and in the US the Census Bureau put the figure for Americans at $60.1 \%$. Taken together, these data seem to suggest that by and large the great majority of billionaires are not only men ( 8.4 male to 1 female) but married men, much more so than the average population.

Marriage is clearly important to these men, because it is a fundamental vehicle for the production of the future generations of elites. Indeed they appear to be substantially better than average at being or remaining married; the available data was not detailed enough to understand how many times the individuals in question had been married, but from my own qualitative research on succession and family offices (Glucksberg and Burrows 2016) it was clear that divorces are frowned upon and avoided at all cost because of the threat of splitting the family's capital. Stable and long-lasting marriages are seen as integral to a 'successful' dynasty-making project.

The ethnographic data presented in this chapter will show how much labour the women invested in these marriages, how they eschewed the development of their own careers for the sake of their families and in general accepted gendered norms that seemed hugely outdated in their patriarchal character. This is not, however, a new feature of elite women's lives. In 1984, Susan Ostrander wrote what she defined as the first study to focus on women of the American upper class, specifically focussing on their labour to preserve and strengthen their marriages at all cost. In this book she argued how:

"The work done by upper class women is largely invisible: that is, it is unpaid and occurs outside the economic marketplace and labour force. Therefore, the women's role in creating and maintaining the economic and political power of the upper class is not typically recognised."

(Ostrander 1984:140; italics are mine) 
Exploring the ways in which elite women understood their own lives through lengthy interviews and engagement with them, Ostrander showed how key their labour - though invisible and unpaid - was in maintaining and reproducing their own individual, families and class position of privilege and power in American society. She also focused on interplays between the gender roles that these women played - broadly speaking they obeyed traditional, conservative gender norms that saw them being submissive and accommodating towards their husbands' needs and wants - and their superior class positioning vis a vis the rest of society, where they were powerful, established upper class women fully aware of their privileged positions.

Her argument was that the women accepted to be 'inferior' in gender terms within their marriages, and submissive to their men, because to oppose these norms would have meant to challenge the class structures that those men were upholding. The women had no intention of doing this because they rather enjoyed being privileged and upper class: the push towards gender liberation was never strong enough to overcome the fear of losing class positioning by challenging their husbands' upholding of patriarchal norms.

From the second half of the 1980s, Yanagisako (2000) has been studying wealthy entrepreneurial families engaged in silk production in the north of Italy. Her work describes, although with clear variations due to the different cultural landscapes of Italy and the US, similarly strict attitudes to gender roles and how women should relate to their families and society at large.

"Bourgeois gender ideology rendered female independence an oxymoron" (2000:59), explains Yanagisako: daughters are seen as a loss to the family business, because they will 'belong' to the family they will marry into. Nonetheless the biggest threat they represent is their potential willingness to claim a share of the family business as inheritance - to which they would be entitled to by law - and therefore they are socialised from very early on away from the operational family business and towards the social and relational side of the family, which is just as important and run entirely by the women.

The socialization of elite women was something that Bourdieu (1996) considered as well, linking it to the successful reproduction of elites through the right marriages, the incorporation of the correct sort of women into the family tree:

"Admitting into the family only those women who are capable of embodying and inculcating respect for bourgeois virtues - the work ethic, an eye for saving, family spirit - fulfils a function entirely similar to the exclusivism that leads to the choice of private educational establishments and highly selective meeting places."

(Bourdieu 1996: 281) 
Reflecting on issues of gender and inheritance in the context of Portuguese elite families, Pedroso de Lima articulates the complex way in which family members are not just chosen but constituted to continue the dynastic line:

"We are not dealing with a univocal transmission process, where continuity is a reproduction of the past. In fact we are dealing with a constituting process in which the new conjuncture is built by some members of this emerging generation, who articulate in their action and strategies, references and values from the past [...] in the context of the new needs and values for the present."

(Pedroso de Lima 2000: 41)

Moving away from the family sphere, other authors have looked instead at the work women from elite backgrounds, or in elite professions, or both, perform outside their homes. Rather depressingly, the findings still paint a picture of a dominating patriarchal sets of values that are not only difficult to escape for women, but impact materially on their earning capacities, even at the very top of the financial hierarchy (Atkinson et al 2016).

For example Roth (2003) has shown how women in Wall Street are paid less than their male colleagues even after controlling for all other factors, even within a culture that supposedly idolised money above all else and therefore did not discriminate on grounds of race, religion, gender and so on - or so they'd have liked to believe. Similarly Ho's (2009) ethnography of Wall Street confirms the huge positive biases that exist in favour of white, privileged males to the disadvantage of anyone else, and how the practice of pay via bonuses, which are almost entirely distributed at the discretion of managers without guidelines or supervision, entrenches the inequalities that these firms, and those who work for them, struggle hard to deny.

Ho's detailed work is also useful in showing how "in this flexible, unstructured space [...] racialised and gendered networks strongly affect who is requested for particular deals, who is perceived as 'getting along' with the client" (2009:271). I would like to focus on these 'unstructured spaces' where it is important to 'get along' with the client, and consider the ways in which women perform another function in the reproduction of elites, this time facilitating their economic reproduction by providing the backdrop and necessary sociability in their leisure spaces.

Mears's work (2015) on the VIP club scene in and around New York looks at the roles that 'girls' - a social category that some young women inhabit at a certain time in their lives - play in facilitating men's networking and career climbing. It is the 'girls' role in constituting the spaces that Ho (2009) describes where connections with the clients can be made and cultivated that is particularly of interest here: 
"If you go out with someone who's a business contact, and meet women and party with girls - one of the thing we can enjoy talking about is women, like in following-up with the clients... I've seen it to be a problem for some women in my business ... [Clubbing] is very weird because so much of the fun is around pursuing women. ...A lot of business is won through experiences like this."

Max, 33, Asian American man, Finance associate

(Mears 2015: 13)

As will be shown in the ethnographic case studies, the work I conducted resonates strongly with that of Mears (2015), and my own data reflect the same importance for young girls in constituting the sort of exclusive - for older women, especially - spaces where men can relax, have fun and cultivate their personal networks, which they will in turn capitalise on in their business capacity. Following Bourdieu's (1984) work on the concept of embodied capital, and Skeggs (2004) revisiting of it in a feminist key, Mears (2015) describes these processes as "the uses of women's bodily capital by men who appropriate women as a symbolic resource to generate profit, status, and social ties in an exclusive world of businessmen."

\section{Methodology}

The research upon which this paper is based was conducted as part of an ESRC funded project looking at the effect of global wealth on the most elite areas of London. Methodologically the research was based on a geodemographic framework (Burrows, 2013): this meant using a software, called Mosaic, which used complex data sets to determine the likely demographic and socio-economic composition of any given neighbourhood in the UK. The objects of study were the areas that Mosaic had identified as "Alpha Territories", inhabited by "groups of people with substantial wealth who live in the most sought after neighbourhoods in the UK".

The aim of the project was to respond to the call for the social sciences to start taking the 'super-rich' more seriously (Beaverstock et al, 2004; Hay and Muller, 2011). It tried to capture the change happening in these areas, following a 'spatialization of class' approach (Burrows and Gane, 2006; Parker et al, 2007; Savage et al, 2005; Baque, Bridge et al, 2015), and to assess the impact of the huge flows of global financial capital on these neighbourhoods, their inhabitants and communities.

An anthropological approach based on ethnography was crucial in creating a successful methodology to go beyond what had been done before. Starting from anthropology's approach to the elites (Nader 1972, Shore and Nugent 2002, Abbink and Salverda 2012, Carrier and Kalb, 2015) the research was developed in a way that was sensitive to what Khan (2012) calls embodied privilege in his close-up, ethnographic study of elite adolescents in the US, or Schimpfossl (2014) adopts to look at elite Russians and philanthropy. 
The areas studied loosely corresponded to what estate agents call prime London (where properties sell for above £2m) and sit in a crescent that goes from Chelsea in the south, up through South Kensington, Knightsbridge, Belgravia, Mayfair, Notting Hill and Holland Park, Hampstead and Highgate in the north. Areas outside of the centre of London but still considered by the project were located around Esher, Cobham and Virginia Water, well known for claiming the top spots in the most expensive house prices in the UK outside of London (Guardian, 11 July 2015).

The project included a number of senior academics from various disciplines in the social sciences - sociology, criminology, anthropology, geography and geo-demographics -and lasted two and a half years. Collectively over one hundred individuals were interviewed, including elite residents as well as a broad spectrum of service providers were actively sought as well, from designers to estate agents, from asset managers to art dealers, from beauticians to carers and florists. Observations and participant observation when possible were used as well.

\section{Ethnographic case studies}

The ways in which economic capital and elite status is produced and re-produced are profoundly gendered in nature, and heavily reliant on the work of women. The first case study I present here is a story of Mayfair by night, of raw financial capital socialized in night clubs through textbook conspicuous consumption, which required - amongst other things being consumed - the bodies of 'girls' to make the night a success. In this section I contextualize my work by using Mears's (2015) account of 'girls' in the VIP scene around New York, Los Angele, Cannes and St. Barts. The second one focuses on women in the suburbs and their work, whether in property development as a side line or, much more importantly, in taking care of the home front and ensuring that their children excelled academically and socially. Given the obvious restrictions dictated by the format, all I am trying to achieve here is beginning to focus on embodied, material and gendered forms of elite reproduction as auspicated by the Gens manifesto (Bear et al) through some initial, ethnographic based evidence.

\section{Young flesh and charity auctions}

"We were told to strut, there was a catwalk, and they played "Blurred Lines"1 as we entered the room."

\footnotetext{
${ }^{1}$ Blurred Lines is a notorious pop song that explicitly engages with issues of consent, rape and violence in relationships.
} 
The girls were young, mostly in their early twenties, some were still teenagers. They had been recruited through modelling agencies, assessed on their 'stats' - not just height and weight, but specific measurements of their thighs, ankles and chests, for example - and then graded by a hostess who would decide whether they would stay for the after party or, later, for the after-after party, upstairs in the men's penthouses. This is standard, they were not surprised by this, nor by the fact that they were told to leave their phones in their bags, which were then taken away from them for the duration of the evening. The reason is the privacy of the guests of course, who would not like photographs taken, and the fact that the girls are paid to work, not be on their phones: and yet, my respondent explained, what if anything had happened and they needed to call for help?

They were given two large glasses of wine to drink, quickly, before entering the ballroom in the tiny, revealing black dresses the agency had provided for them. Their instructions were to entertain the men, get them to drink but most importantly get them to bid and spend large amounts of money. This was an auction after all: a charity auction held in one of the most prestigious hotels of Mayfair, the heart of London's financial district (it is here that hedge funds and private equity firms are mainly based; it is here that the family offices that advise the most powerful families in the country, and possibly on the planet, base themselves). The men were there for what are usually known as 'male only charity events', and the role of the girls was to increase the amount they would bid. The girls were encouraged to sit on the men's laps, flirt with them - look at them directly in the eyes, the hostess told them - and generally flatter them into making substantial bids.

Nothing in this set up is surprising if one is familiar with the night life of Mayfair, where clubs jostle for control of the prettiest and youngest girls to attract the wealthiest men and get them to spend very substantial amounts of money on drinks. This sort of entertainment is provided routinely to investors and business partners, who are wined, dined and entertained to build and cement networks and business relationships. This part of Mayfair by night is crucial to the operation of the financial centre by day, yet it is hardly ever talked about. Young women's flesh remains one of the main conduits through which the raw financial capital produced in the deals is socialized and dispersed.

The young women in question crucially do not get paid: they are taken out by promoters and their expenses are paid for: entry to the club, drinks, sometimes dinner. The promoters do get paid, by the clubs, according to how many girls they bring, and of what 'quality': the girls are assessed on their looks, with the best possible look being that of a fashion model, i.e. as tall and as skinny as possible. So the promoters try to bring out as many of the best girls as possible, to get paid by the clubs: the clubs want the girls in order to attract wealthy men who will then spend money on drinks, which is where the clubs make their profits. It is well known on the scene that the best clubs are those with the best crowd, meaning the most beautiful girls, who bring the wealthiest guys, who pay for crazy drinks and, together with the promoters, make great parties happen. 
The girls I spoke to in this scene were students at very prestigious universities in central London, and were often themselves from elite, privileged families. The obvious question for me was why they would accept to go out with the promoters on these terms, i.e. without being paid, while they were clearly generating money for the clubs. The explanations varied, and are consistent with the business model required by the clubs. Many girls would not actually be on the scene for a long time; they would like the novelty of going out for free, but then get bored with it, or need to focus on their studies, or get into relationships that would take them away from clubbing. This suited the promoters, who were always after new girls, fresh faces and bodies to please the clubs.

Another explanation focused on the ambiguities that young women would experience around their relationship with the promoter as friend but also maybe a potential boyfriend. Once it became clear to the girl that he was not interested in her in that way, she may well stop going out: these ambiguities also suited promoters as they kept girls coming out with them. In one case, a young woman who used to go out for fun started using the scene as an object of sociological study for her dissertation instead, subtly subverting the narrative - with which I agree entirely - that sees girls as usually unable to capitalize on these transactions, described by Mears (2015).

Mears (2015) has described these processes in great detail in relation to the VIP club scene in and around New York, arguing that 'girls' is a social category that some young women inhabit at a certain time in their lives in a certain socio-cultural setting. Crucially, 'girls' are unable to capitalize on their own value, based mainly on their looks, which is instead appropriated and turned into economic and social capital, in the form of profits, salaries and networks for the clubs, promoters and clients who enjoy the girls' presence.

Santos (2013) describes similar patterns in Johannesburg clubs through an anthropological framework that connects money, power and music as rituals to further bring forward wealth within the club. When individual bottles of champagne in Mayfair routinely sell for over £10K, and are accompanied by crews of young, thin and beautiful female bar staff with sparklers and theme music - known as champagne trains - in the most exclusive clubs, the excesses of JG Ballard novels seem relatively tame. It is indeed hard not to think about potlaches (Mauss 1924) and creative disruption (Schumpeter 1949) in relation to these flows and exchanges between money, youth, flesh, power and excess consumption.

In this context, it is key to stress how young women perform an essential task in generating money for the clubs, but also literally creating a conducive atmosphere to male relationship bonding which then generate networking and business deals for the male clients. A passage by Mears (2015) here describes this situation very clearly, also highlighting the two omnipresent threats of being a) associated with paid sex work, something that both girls and promoters want to avoid at all costs and $b$ ) being seen as deviating from the heterosexual norm. 
"Most clients and promoters simply believe that a room full of men is less comfortable than a room with girls, explained Artem, a Russian male model promoting in Hong Kong and NYC:

Sometimes management calls me or big guys calling like, "Hey I have clients in town..." Because it's five guys, with a magnum of champagne, and they look like fucking faggots. "So please," they say, "get us the girls." So it's not like prostitution and shit like that. They don't even talk to the girls... They just look nice, and it breaks the ice, to get comfortable." -

Artem, 28, White promoter for three years, from Russia

These clubs constitute spaces that are exclusive not just of non-heterosexual men, as obvious in the quote, but also of female bodies that are not young, thin and model like. They are not open to business women, for example, regardless of how wealthy and successful they may be, because they are unlikely to be young and thin enough to be allowed through the ruthlessly screened doors. Elite London in this sense can be seen as a social space structured around strong hierarchies not just of class but also gender, intersecting to create what a respondent in the project, a rich, successful business woman, termed 'patriarchy on steroids'.

In this case study young women were key to the night time economy of VIP clubs and parties, which is literally predicated upon their bodily capital, used to socialize and redistribute the financial capital pouring out of successful deals in the City. What is more their work enabled and facilitated the formation and development of elite men's networks, by providing the right atmosphere and backdrop where they could relax and strengthen their own relationships, which we know to be a crucial part of elites' reproduction strategies. We now move on to a very different set of case studies where women's work is more closely aligned with the traditional idea of gendered reproduction, i.e. the care for their family, home and, most of all, the achievements of their children.

\section{2. "They juggle a lot of balls up in the air, and if they fall it's a long way down"}

Symbolically and socially opposite to the 'girls' as a category, and geographically removed from the clubs of central London that their men patronized after work, were 'the wives', living in big houses in the suburbs. Unsurprisingly, these women turned out to be diverse and not very much like the stereotypes of the 'ladies who lunch'. They knew the stereotypes very well of course, and played with them. Their houses were undoubtedly big and expensive: big gardens, many rooms, often a swimming-pool in the grounds, or the basement, or both. They all had staff, some more than others. The women who said they did not have staff usually meant that they did not live in: it was a given that it was not them who were cleaning the houses or looking after the gardens. 
What they wanted to get across, in all of the interviews, was that being them was not easy. Managing their homes and ensuring the smooth climb of their husbands' careers by taking care of absolutely everything else was a demanding job, and their husbands were used to efficient and effective staff themselves. Indeed, in a popular but well researched book, academic turned journalist Wednesday Martin (2015), has recently shown how some elite wives of New York routinely get 'bonuses' according to how they have performed that year and whether the children have got into the right schools, for example. While I did not find any evidence of this myself, the set up I observed would make it eminently plausible, and possible.

It was routine for these women to leave their career when they had children: this was not always their preference, but it was clear to them that their husbands were not going to advance in their careers unless 'the home front' was taken care of, meaning that there had to be a wife to look after everything else, leaving the man free to work and socialize with the clients unencumbered by any caring responsibility. Things seem to not have changed substantially from over thirty years ago, when Ostrander (1984) was describing exactly the same processes being at play for upper class American women in the early Eighties.

They were not all wives, and not all of them had children; a minority had made money independently, but the majority were wealthy through their husbands, current or past, or through inheritance and divorce settlements. The kind of settlements that shake the stock market, because their CEOs husbands have to flood the market with shares in order to pay out what they owe their wives.

One of them was called Natasha: she was Russian and had lived through the collapse of the USSR, having to re-invent herself as a hotel manager after abandoning a promising career as a scientist. She had a PhD and worked in a hospital, but after months of her salary going unpaid and no prospects of things getting better, she emigrated to Germany and changed her career entirely, becoming so successful in her new role that she travelled the world on business, which is how she met her current, rich husband. As many of the women interviewed, she had a successful career before her marriage, and she now uses the skills and education she had to make sure her children succeed in every possible way, which for now means doing well in their education.

Talking incredibly fast, she ploughed through the weekend schedule of her three children, which sounded more demanding than what most adults would take on during a working week, let alone a weekend. They all attended top ranking private schools, of course, but also excel at ballet and rugby and are fluent in Russian; there are sessions in all these, and more, disciplines for each child every weekend. There is not much time left at the end of it all: "we just don't get to sit in front of the sofa and relax. I don't know how people do it, where do they find the time?". She is responsible for taking the children to the activities, selecting the classes and monitoring the instructors, as well as hiring the tutors for extra sessions in any subject that they may not be at the top of the class for. She explained how the real cost of private 
school was not the fees, oh no, she pitied the poor parents who think that's it, they kill themselves to get the children through the door without realizing the obscene amount of money required for extra tuition and activities, without which there is absolutely no point in sending them there at all. "They just don't know, but someone should tell them!"

Most of the women do more than run the children's education, usually entirely on their own because the husbands work incredibly long hours. They also run their homes, managing staff and cycles of endless decorating required to keep the house as it should be, whether for entertainment purposes - deals may require inviting clients at home - or to keep the value of those properties stable or going up. Many work in property development as a side line, making considerable amounts of money selling and developing properties, often through the networks that they have established around themselves while simply looking like 'ladies who lunch'.

All the same, their standard response to questions about what they do is that they do not do anything, it is their husbands who work: their own labour, crucial as it is to the successful reproduction of the next elite generation, is often unrecognized even by the women who perform it. In her work with rural women in Poland after the collapse of the Soviet Union, anthropologist Frances Pine (2000) showed how farm labour was not thought of as 'labour' or work, as such, by the women. Although it took up a very considerable amount of hours in their daily lives, while they were also employed full time in industry and usually caring for their families, farming was not something that women 'did', as such: it was enmeshed in kinship and not separable as a practice, as it was for men instead, who were farmers and recognized as such by themselves and society at large.

It is easy to miss important parts of what is happening in a given situation for a researcher, even more so if the respondents themselves do not think of that something as a 'thing' in and of itself. Back in the exclusive suburb, as far away from rural Poland as could be, the women talked about themselves jokingly as 'ladies who lunch'. They knew the stereotype, they knew they were privileged, and they played to the role, explaining how they did nothing really, just met their friends for coffee. Only, it was never just that. The nothing may well include moving an entire family to a different country at almost no notice, over the Christmas holidays, because of a promotion received by the husband: "Just make it happen" he said. "So of course, I did it".

\section{Analysis}

The successful transfer of wealth from one generation to the next is a key concern of the very wealthy, especially at a time when the weight of accumulated capital plays an ever greater part in individuals' likeliness to belong to the top of the elite usually referred to as 'the superrich'. Savage (2015) uses the image of climbing mountains as a metaphor for achieving elite status, stressing how much easier it is to get to the top for those who start higher up, and can afford the best kit. 


\begin{abstract}
"What we have seen in Britain - as in many nations - is an increasingly vertiginous social landscape, with a lot more total economic capital - a lot more rock and earth - and with the highest mountains now rising much further above the valley than they did three decades ago. [...] In the competition to get to the top, however, those who join the meritocratic route to the summit from the highest base camp have much better prospects of getting to the top. [...] Their chances are even better if they can mobilize and combine every advantage possible - their economic, social and cultural capital - so that they have the most effective kit on their arduous adventure."
\end{abstract}

(Savage 2015: 188-189)

The examples explored in this chapter showed very clearly how women's labour enabled and facilitated the climbs of men. On the one hand they covered 'the home front', taking care of absolutely everything so that their men could focus on their work, just as the upper class women described by Ostrander (1984) did in the seventies. Secondly they invested heavily, to the point of leaving their own paid careers - their chance to climb the slopes independently - in the education and all round development of their children, ensuring not just access to the best school but also monitoring performance and facilitating their social activities. In this sense, if we continue with the climbing metaphor, they made sure the base camp for the next generation was as high up as possible, and literally carried their children there. Thirdly, in a different context, their labour created a functional backdrop where men could forge their own exclusive business and friendship networks without ever breaking hetero-normative requirements. Indeed, the practice of pursuing 'girls' in the clubs reinforced the executives' selves as highly masculine and hyper achieving and successful.

Intertwined with these very obvious contributions, however, was the realization of how the labour performed was usually invisible and un-recognized, even by the women who performed it themselves. This misrecognition - the party girls who are just out to have fun, or the mothers who are just looking after their children - is in a sense in-line with the devaluation of all domestic and reproductive labour, which is usually but not always performed by women. This devaluation is in itself typical of a patriarchal paradigm whereby it is only 'productive' labour that takes place outside the household that is recognized - both in terms of a salary but also of being seen, i.e. being perceived as socially valuable.

This devaluation is also in line with the surprisingly - for the author, at least - rigid gender roles and norms that I witnessed in the course of fieldwork. Mistakenly I assumed that being wealthy and often having at their disposal substantial amounts of economic, social and symbolic capital themselves - even if it was less than what their men commanded - would mean the women would be less in thrall to patriarchal norms. In reality those norms were even more rigid the further up the social hierarchy I moved: the strictly policed boundaries of morality - what is acceptable for 'party girls' in terms of having fun but never accepting gifts in cash, for example; the double standards expected by the business men who partied with 
the girls while their wives in the suburbs looked after the children; the expectations that the only truly correct choice for elite girls - the daughters, in this case - was marriage and children, and so on.

More than thirty years ago, Ostrander (1984) concluded that upper class US women accepted subordination to their husbands, instead of challenging the norms that the sexual revolution of the sixties and counter-culture of the seventies had put under considerable amount of pressure, because in doing so they preserved their privileged class position. Although I cannot come to such an explicit conclusion myself, because I did not frame the research in a way that would allow me to do so, I strongly suspect that a similar dynamic may still be at play amongst the elite women that were the focus of this chapter. At the very least, this data makes the case for the need to focus much more on the interplay between gender and class in elite contexts.

\section{Conclusion}

Dynasty making is a key concern of elite families: it is pursued through long-lasting, successful marriages as well as the most tax efficient transfers of inheritances. It is bound up with children's education as well as their broader socialization and, eventually, their own appropriate, class compatible marriages. Just as economic capital needs to be protected and increased, so does the family. These are long term, intergenerational concerns that fit well with Savage's (2015), Piketty's (2014) and Khan's (2012) focus on the long duree of accumulation processes and the structural, as well as cultural, processes that make elite reproduction possible.

The data presented in this chapter showed how in the key processes of transfer and reproduction of wealth, and of the humans able to manage and grow that wealth, women's work is clearly central. I have focused on the how, and in doing so have opened up spaces to consider, this time, the two seemingly antithetical categories of 'girls' and 'mothers'.

The intense, gendered labour of these women may well be at least partly responsible for the above average marriage rates that billionaire men seem to achieve. In the same way women's work - invisible as it may be (Ostrander 1984) - is crucial in placing and helping of children achieve their potential through exclusive, private educational establishments. Finally the 'girls' (Mayers 2015) role was crucial in constituting the spaces where masculinity could be performed as a male bonding strategy amongst business executives.

In light of this data, elite London has emerged as a social space structured around strong hierarchies not just of class but also gender. I would therefore argue that it is essential to understand more about the interplay of these two structuring principles within elite spaces, focusing on the 'invisible' labour performed by elite women. 


\section{Bibliography}

Abbink, J. and Salverda, T. (eds.) (20130.) The Anthropology of Elites: Power, Culture and the Complexities of Distinction New York: Palgrave Macmillan.

Bacque, M., Bridge, G., Benson, M., Butler, T., Charmes, E., Fijalkow, Y., Jackson, E., Launay, L., Vermeesch, S. (2015) The middle classes and the city: a study of Paris and London. Houdsmill, Basingstoke: Palgrave.

Beaverstock, J., Hubbard, P and Short, J. (2004) 'Getting away with it? Exposing the Geographies of the Super-Rich', Geofurum, 35, 401-407.

Bourdieu, P. (1984) Distinction: A Social Critique of the Judgment of Taste, London: Routledge and Kegan Paul.

Burrows, R. and Gane, N. (2006) 'Geodemographics, Software and Class', Sociology, 40, 5: 793-812.

Burrows, R. 2013 "The new gilded ghettos: the geodemographics of the super-rich" http://discoversociety.org/2013/12/03/the-new-gilded-ghettos-the-geodemographicsof-the-super-rich/

Carrier, J. G. and Kalb, D. (eds) (2015) Anthropologies of Class: Power, Practice and Inequality Cambridge: University Press.

Dorling, D. (2014) Inequality and the 1\% London: Verso.

Glucksberg, L. and Burrows, R. (2016) "Family Offices and the Contemporary Infrastructures of Dynastic Wealth" in Sociologica (in press/forthcoming).

Hay, I. and Muller, S. (2011) 'That Tiny, Stratospheric Apex That Owns Most of the World' - Exploring Geographies of the Super-Rich', Geographical Research

Khan, S. (2012) Privilege: The Making of an Adolescent Elite at St. Paul's School Princeton: University Press.

Khan, S. (2012) "The Sociology of Elites" Annual Review of Sociology (38) 361-77.

Martin, W. (2015) Primates of Park Avenue: A Memoir New York: Simon and Schuster.

Mauss, M. (1924) [1970] The gift: Forms and Functions of Exchange in Archaic Societies, London: Routledge.

Mears, A. (2015) "Girls as elite distinction: The appropriation of bodily capital" Poetics.

Mizruchi, M.S. (2013), The fracturing of the American corporate elite, Harvard University Press.

Nader, L. (1972) 'Up the anthropologist: perspectives gained from studying up' in Hymes, D. (ed.) Reinventing Anthropology. New York NY: Vintage. 
Osbourne, H. (2015) "UK Sees Surge in Property Millionaires despite Slowdown in House Market." Guardian, 11 July 2015

http://www.theguardian.com/business/2015/jul/11/uk-sees-surge-in-propertymillionaires-despite-slowdown-in-house-market

Oxfam (2015) Wealth: Having it All and Wanting More Issue briefing. file:///Users/luna/Downloads/ib-wealth-having-all-wanting-more-190115-en.pdf

Parker, S., Uprichard, E. and Burrows, R. (2007) 'Class Places and Place Classes:

Geodemographics and the Spatialization of Class', Information, Communication and Society, 10, 6: 901-920.

Piketty, T. (2014) Capital in the 21st Century Harvard: University Press.

Pine, F. (2000) "Kinship, gender and work in a Polish highland village" in Goddard, V. (ed) Gender, Agency and Change London: Routledge.

Rosplock, K. \& Hauser, B.R. (2014) 'The Family Office Landscape: Todays Trends and Five Predictions for the Family Office of Tomorrow', The Journal of Wealth Management, 17(3), pp. 9-19.

Santos, D. (2013) "All mixed-up: music and inter-generational experiences of social change in South Africa" Doctoral Thesis, Goldsmiths, University London.

Savage, M., G. Bagnall, et al. (2005). Globalization and belonging. London, Sage.

Savage, M. (2015) Class in the $21^{\text {st }}$ Century London: Penguin Press.

Savage, M. and Williams, K. (2008) Remembering Elites Oxford: Blackwell.

Schimpfossl, E. (2014), Russia's social upper class: from ostentation to culturedness. The British Journal of Sociology, 65: 63-81.

Schumpeter, J.A. 1949 [1976] Capitalism, Socialism, and Democracy, London: Taylor and Francis.

Shore, C. and Nugent, S. (2002) Elite Cultures: Anthropological Perspectives London: Routledge.

Skeggs, B. 2004 Class, Self, Culture, London: Routledge.

Wealth-X and UBS, (2013) World Ultra Wealth Report

Wealth-X (2015-2016) Billionaire Census Highlights

US Census Bureau: Bureau of Labor Statistics (c) Statista 2016

Office for National Statistics, http://www.ons.gov.uk/peoplepopulationandcommunity/populationandmigration/popul ationestimates/bulletins/populationestimatesbymaritalstatusandlivingarrangements/2 $\underline{002 t 02015}$ 